\title{
Margaret McCartney: Cameras and complaints
}

\author{
Margaret McCartney general practitioner
}

Glasgow

An international trial has found that police officers who wore video cameras attracted fewer complaints. Officers were randomly allocated to wear cameras or not; if they did, they told any members of the public they interacted with.

In the year before the study the police received 1539 complaints in the seven experimental sites. This averaged 1.2 complaints per officer before the study, which fell to 0.08 when they were wearing cameras. ${ }^{1}$ Importantly, however, no statistically significant difference was seen in the number of complaints between the control and treatment groups, leading the authors to conclude that the decrease in complaints about camera-wearing and non camera-wearing officers was partly due to "contagious accountability."

The medical community globally has been asking whether doctors should be doing the same thing. As litigation costs rise, could digital video recording of all clinical encounters reduce complaints against healthcare staff?

Cameras are already used daily by many commuter cyclists, and arguments rage about whether they represent a sartorial act of aggression or a defensive mechanism against a hostile world.

Let's be clear: in most instances recording medical consultations, like having a chaperone present, will aim to protect the doctor, not the patient. General practice, however, has a long history of using cameras to record consultations for training and to improve care. Many out-of-hours services routinely record telephone consultations. And we hear calls for more patients to record their consultations, in the belief that the information will be of use and patients can listen again. Covert recording is something GPs have been advised to expect—and told that they can't prevent. ${ }^{2}$

But doctors aren't police officers. Complaints about the police are likely to be quite different from those about doctors, including concerns about the use of force. The public will also behave differently. Cameras, which were switched on constantly in the trial, may reduce bad behaviour on the part of the public and the police. In medicine we expect differences in purposes and outcomes between professionals and patients. Recording consultations has been found to be of great value to patients attending oncology appointments, ${ }^{3}$ and it's easy to see why: information about complex choices is distilled into consultations, and it's well known that that patients' recall is difficult. ${ }^{45}$

Video recording could flush out poor medical practice.

It may also show policy makers the impossibility of practising good medicine without time and resources

I know that the putative aim is to make life easier by protecting myself against an unjustified complaint; but, ironically, I worry about not being perfect. (I suffer recurrently when catching myself on the radio, knowing that I could have phrased something better.)

Video recording could flush out unacceptably poor medical practice. It may also show policy makers the impossibility of practising good enough medicine without enough time and resources.

But it will also place stress on all of us who are imperfect humans in an inhumane system. And it could have unintended effects on the way patients present themselves or disclose or discuss symptoms. Ultimately, is the intention to protect doctors or patients? And who will be harmed while others gain?

Competing interests: See www.bmj.com/about-bmj/freelancecontributors/margaret-mccartney.

Provenance and peer review: Commissioned; not externally peer reviewed.

Follow Margaret on Twitter, @mgtmccartney

1 Ariel B, Sutherland A, Henstock D, et al. "Contagious accountability": a global multisite randomized controlled trial on the effect of police body-worn cameras on citizens' complaints against the police. Crim Justice Behav2016; doi:10.1177/0093854816668218.

2 Medical and Dental Defence Union of Scotland. Covert recording of consultations. $31 \mathrm{Ma}$ 2015. www.mddus.com/risk-management/risk-alerts/2015/march/covert-recording-ofconsultations/.

3 Tsulukidze M, Durand MA, Barr PJ, Mead T, Elwyn G. Providing recording of clinical consultation to patients - a highly valued but underutilized intervention: a scoping review. Patient Educ Couns 2014;95:297-304. doi:10.1016/j.pec.2014.02.007 pmid:24630697.

4 Marty $\mathrm{H}$, Bogenstätter $\mathrm{Y}$, Franc $\mathrm{G}$, Tschan F, Zimmermann $\mathrm{H}$. How well informed are patients when leaving the emergency department? comparing information provided and information retained. Emerg Med J 2013;30:53-7. doi:10.1136/emermed-2011200451 pmid:22411594.

5 Kessels RP. Patients' memory for medical information. J R Soc Med 2003;96:219-22. doi:10.1258/jrsm.96.5.219 pmid:12724430.

Published by the BMJ Publishing Group Limited. For permission to use (where not already granted under a licence) please go to http://group.bmj.com/group/rights-licensing/ permissions 
